\title{
A fully floating system for a wave energy converter with direct-driven linear generator
}

Yuping Gao ${ }^{\mathrm{a}, \mathrm{b}, \mathrm{c}}$, Shuangquan $\mathrm{Shao}^{\mathrm{a}, \mathrm{b} *}$, Huiming Zou ${ }^{\mathrm{a}, \mathrm{b}}$, Mingsheng Tang ${ }^{\mathrm{a}, \mathrm{b}}$, Hongbo $\mathrm{Xu}^{\mathrm{a}, \mathrm{b}}$, Changqing Tian ${ }^{\mathrm{a}, \mathrm{b}}$

${ }^{a}$ Key Laboratory of Cryogenics, Technical Institute of Physics and Chemistry, CAS, Beijing, 100190, China

${ }^{b}$ Beijing Key Laboratory of Thermal Science and Technology, Technical Institute of Physics and Chemistry, CAS, Beijing, 100190, China

${ }^{\mathrm{c}}$ University of Chinese Academy of Sciences, Beijing, 100049, China

*Corresponding author. Tel.: +86 1082543433.

E-mail address: shaoshq@ mail.ipc.ac.cn (S.Q. Shao)

\section{ABSTRACT}

Wave energy is one of the most promising renewable energy for power generation. This research develops a novel power take-off methodology to surmount the problems associated with mooring, seawater corrosion and access for maintenance in conventional wave energy converters (WEC) with direct-driven linear generators. Its prototype consists of two bodies, the floating body acting as a buoy to extract the wave energy, while the inner body undergoes a forced oscillation, whose relative motion generates the electronic power. Its feasibility is investigated theoretically by coupling the dynamics of the wave, the floating and the inner bodies and the electromagnetic characteristics of the linear generator. As a result, the generator can induce a highly sinusoidal voltage. Furthermore, the performance of the system is investigated in detail 
under different conditions. The results show that, a resonance has been achieved in the case with the spring constant of $12633 \mathrm{~N} / \mathrm{m}$, with a maximum power capture ratio of $57 \%$. The performance of the system is shown to be sensitive to the load resistance, the wave height, and the spring constant.

KEY WORDS: wave energy converter; direct-driven linear generator; resonance; power capture ratio

\begin{tabular}{|ll|}
\hline Nomenclature & \\
$a$ & wave amplitude $(\mathrm{m})$ \\
$C$ & water plane area $\left(\mathrm{m}^{2}\right)$ \\
$D_{l}, D_{2}$ and $D_{3}$ & damping coefficient caused by mooring system $(\mathrm{N} \cdot \mathrm{s} / \mathrm{m})$ \\
$e$ & diameters of the air gaps $(\mathrm{m})$ \\
$E$ & induced voltage $(\mathrm{V})$ \\
$f_{e}$ & effective value of induced voltage $(\mathrm{V})$ \\
$F$ & non-causal impulse response function $(\mathrm{N} / \mathrm{m})$ \\
$g$ & force $(\mathrm{N})$ \\
$g_{l}$ and $g_{2}$ & gravitational acceleration $\left(\mathrm{m} / \mathrm{s}^{2}\right)$ \\
$H$ & air gaps $(\mathrm{m})$ \\
$i$ & wave height $(\mathrm{m})$ \\
$I$ & electric current $(\mathrm{A})$ \\
$I_{m}$ & effective value of current $(\mathrm{A})$ \\
$k_{e m}$ & current amplitude $(\mathrm{A})$ \\
$k_{s}$ & electromagnetic force coefficient $(\mathrm{N} / \mathrm{A})$ \\
$k_{w}$ & spring constant $(\mathrm{N} / \mathrm{m})$ \\
$L$ & wave constant $\left(\mathrm{W} /\left(\mathrm{m}^{3} \cdot \mathrm{s}\right)\right)$ \\
\hline & Inductance $(\mathrm{H})$ \\
\hline & mass $(\mathrm{kg})$ \\
\hline & coil turns \\
\hline & power $(\mathrm{W})$ \\
\hline &
\end{tabular}




\begin{tabular}{|c|c|}
\hline$R_{d}$ & radiation damping coefficient $(\mathrm{N} \cdot \mathrm{s} / \mathrm{m})$ \\
\hline$R A O$ & response amplitude operator \\
\hline$S_{b}$ & buoyancy stiffness (N/m) \\
\hline$s+l$ & half of the length of the air gap (m) \\
\hline$t$ & time $(\mathrm{s})$ \\
\hline$T$ & wave period (s) \\
\hline$T_{r}$ & relative motion transmissibility \\
\hline$x$ & Displacement (m) \\
\hline$\dot{x}$ & Velocity (m/s) \\
\hline$\ddot{x}$ & Acceleration $\left(\mathrm{m} / \mathrm{s}^{2}\right)$ \\
\hline$X_{m}$ & displacement amplitude (m) \\
\hline$z$ & thickness of the permanent magnet (m) \\
\hline \multicolumn{2}{|c|}{ Abbreviations } \\
\hline AWS & Archimedes Wave Swing \\
\hline FEM & Finite Element Method \\
\hline KVL & Kirchhoff's Voltage Law \\
\hline Nd-Fe-B & Neodymium-Iron-Boron \\
\hline OWCs & Oscillating Water Columns \\
\hline PTO & Power Take-Off \\
\hline WEC & Wave Energy Converter \\
\hline \multicolumn{2}{|l|}{ Greek } \\
\hline$\omega$ & angular frequency (rad/s) \\
\hline$\rho$ & density $\left(\mathrm{kg} / \mathrm{m}^{3}\right)$ \\
\hline$\eta$ & wave elevation (m) \\
\hline$\Phi$ & magnetic flux (Wb) \\
\hline$\varphi$ & phase angle (rad) \\
\hline$\triangle \varphi$ & phase difference (rad) \\
\hline \multicolumn{2}{|l|}{ Subscript } \\
\hline 1 & floating body \\
\hline 2 & inner body \\
\hline$a$ & added \\
\hline$d$ & damping \\
\hline
\end{tabular}




\begin{tabular}{|ll|}
\hline des & design \\
$e$ & excitation or electrical \\
$g$ & electromagnetic \\
$h$ & generator \\
$i$ & hydrostatic \\
$l$ & current \\
$n$ & load \\
$r$ & nature \\
$r a t$ & radiation or relative \\
$s$ & ratio \\
$t$ & spring \\
$w$ & total \\
$x$ & wave \\
\hline
\end{tabular}

\section{Introduction}

Nowadays, with global attention being drawn to climate change and the rising level of $\mathrm{CO}_{2}$, the focus on generating electricity from renewable sources is once again an important area of research [1-3]. Among the emerging electrical power generation choices from renewable energy, the energy included in the oceans is one of the most promising $[4,5]$. Among the different forms of ocean energy, wave energy is the most conspicuous [6]. Waves are generated by winds, which in turn are generated by solar energy [7]. The potential worldwide wave energy resource is estimated to be $2 \mathrm{TW}$ [8].

A number of different power take-off (PTO) mechanisms connected to the wave energy converter (WEC) have been studied, such as hydraulics, turbines, and direct-driven linear generators. An example of the WEC with hydraulics is the Pelamis [9]. The types of devices using turbines include oscillating water columns (OWCs) and 
overtopping devices. For instance, the LIMPET on Islay is a case of OWCs [10]. Both hydraulics and turbines act as a form of gearing to match the low-speed reciprocating motion of the wave device to high-speed rotary motion to drive conventional rotary electrical generators. It is argued that the increased complexity of hydraulics or turbines systems introduces reliability and maintenance issues [11,12]. The direct-driven linear generators offer the possibility of directly converting mechanical energy into electrical energy, with no intermediate steps between the primary interface and the electrical machine. During early researches, the direct-driven linear generators were considered as too heavy, inefficient, and expensive [13]. However, with the development of high-energy density permanent magnets, such as Neodymium-Iron-Boron (Nd-Fe-B), and the reduced costs of frequency converting electronics, the advantages of the direct-driven linear generators become more obvious [14].

A diversity of direct-driven linear generator systems has been developed for WEC. The Archimedes Wave Swing (AWS) was the first WEC using a linear electrical generator [15]. It is a fully submerged heaving device and consists of a floater and a basement, as shown in Fig. 1. The floater is pushed down under a wave crest and moves up under a wave trough. A prototype of the AWS was deployed and tested at the northern coast of Portugal in the second half of 2004 [16].

Another direct-driven linear generator system was developed by Waters, as shown in Fig. 2. Its prototype was installed at a depth of $25 \mathrm{~m}, 2 \mathrm{~km}$ off the Swedish west coast in the proximity of Lysekil [17]. However, this single-body heaving system may raise some difficulties due to the distance between the free surface and the sea bed. Therefore, the two-body heaving systems may be used instead, in which the energy is 
converted from the relative motion between the two heaving bodies. The hydrodynamics of the two-body systems was theoretically analyzed in detail by Falnes [18]. However, additional problems associated with mooring, seawater corrosion, access for maintenance and the need of long underwater electrical cables have hindered their development.

In order to reduce the problems in the conventional WECs with direct-driven linear generators, we tentatively put forward a novel system as an alternative in this paper. We aim to test the feasibility of this system. The performance of the system is investigated in detail under different conditions in the present study.

\section{Physical model}

\subsection{WEC structure}

In consideration of the design constraints, the system is designed according to the R.Redlich motor [19]. The conceptual schematic of the novel WEC is shown in Fig. 3. It consists of a bottom-fixed spar and a floating system. The floating system is free to heave along the spar, but is constrained in all other degrees of freedom by a linear bearing system. The floating system consists of two bodies, the floating body acting as a buoy to extract the wave energy, while the inner body undergoes a forced oscillation. The coils are mounted in the floating body and the permanent magnet is mounted on the inner body. While the floating body is driven to heave by the wave, the inner body will also move in heave. Consequently, the relative motion between the two bodies could induce a voltage in the coils. The system is also equipped with upper and lower end stop springs to protect it from mechanical shock loads in waves higher than the design condition. 
In this design, the whole generator is floating on the ocean surface, with no need for sinking into the sea. Therefore, the problems associated with mooring and access for maintenance have been largely decreased. In addition, the generator in this system is fixed inside the floating body without direct contact with the sea water. Thus, the seawater corrosion can also be neglected.

\subsection{Hydrodynamic analysis}

Ocean waves with an amplitude which is much smaller than the wave length can be described by potential linear wave theory [20]. This assumes an ideal fluid, i.e., incompressible, irrotational, and non-viscous. Since the waves are assumed to have small amplitude compared to the wave length, the dynamic free surface boundary condition can be linearized [21].

The displacement of the floating body is denoted by $x_{1}$. For the body oscillate in the heave mode only, dynamic equation can be expressed as

$$
\left(m_{t}+m_{a}\right) \ddot{x}_{1}=F_{e}+F_{r}+F_{h}+F_{d}
$$

where $m_{t}$ is the total mass of the floating body and inner body, $m_{\mathrm{a}}$ is the added mass, $F_{e}$ is the excitation force, $F_{r}$ is the radiation damping force, $F_{h}$ is the hydrostatic force, and $F_{d}$ is the damping force caused by the mooring system. In terms of complex amplitudes, Eq. (1) can be written as

$$
\left\{-\omega^{2}\left[m_{t}+m_{a}(\omega)\right]+i \omega\left[\hat{R}_{d}(\omega)+\hat{C}\right]+S_{b}\right\} \hat{x}_{1}=\hat{f}_{e} \cdot \hat{\eta}
$$

where $R_{d}(\omega)$ is the radiation damping coefficient, $C$ is the damping coefficient caused by the mooring system, $S_{b}$ is the buoyancy stiffness, $f_{e}$ is the non-causal impulse response function of the excitation force, and $\eta$ is the wave elevation. The caret $\wedge$ denotes the Fourier transform. For a floating body, in general, the buoyancy stiffness is 


$$
S_{b}=\rho g A
$$

where $A$ is the water plane area of the body.

The system's response amplitude operator, $R A O$, in the frequency domain, can be written as

$$
R \hat{A} O=\frac{\hat{x}_{1}}{\hat{\eta}}=\frac{\hat{f}_{e}}{-\omega^{2}\left[m_{t}+m_{a}(\omega)\right]+i \omega\left[\hat{R}_{d}(\omega)+\hat{C}\right]+\rho g A}
$$

According to [15], there are two optimal conditions for the maximum absorbed power

$$
\begin{gathered}
\omega=\sqrt{\frac{\rho g A}{m_{t}+m_{a}(\omega)}} \\
C=R_{d}(\omega)
\end{gathered}
$$

Eq. (5) is the resonance condition. Eq. (6) shows that the optimal damping should equal the radiation damping.

A typical $R A O$ curve is shown in Fig. 4. For the optimal damping condition, there will be a peak for $R A O$ at which the resonance occurs. On the other hand, overdamping produces a less peaky response curve. Whereas, $R A O$ is around 1 no matter it is optimal damping or overdamping at lower angular frequency. The sea state with the greatest contribution to energy has a wave period in the range of $4 \sim 10 \mathrm{~s}$ or a corresponding frequency range of $0.628 \sim 1.57 \mathrm{rad} / \mathrm{s}$ in the Fukue Island [22]. By selecting an appropriate damping, a suitable total mass and water plane area, the resonant feature and frequency of the system can be changed. Therefore within the narrow range of the wave frequencies in the Fukue Island, the system may be tuned to have a $R A O$ approximately 1 . In the later analysis of dynamics, $R A O$ is set to 1 .

\subsection{Parametric design}

The generator has a parameterized geometry as shown in Fig. 5. In this section, the 
parameters for the WEC are determined. Most parameters are shown in Table 1. The other important parameters are determined by calculation or simulation.

\subsubsection{Spring constant}

The floating body has the same frequency as that of the incident wave and it can be expressed as

$$
\omega_{1}=\omega=\frac{2 \pi}{T}
$$

where $T$ is the wave period. The inner body's nature frequency of undamped oscillation is set by its mass and the spring constant as

$$
\omega_{2, n}=\sqrt{\frac{k_{s}}{m_{2}}}
$$

It is obviously that the inner body in resonance with the floating body, i.e., $\omega_{2, n} \approx \omega_{1}$ will achieve increased amplitude of displacement and velocity, and thereby transfer more energy than a system working off resonance. Therefore, the spring constant is set to make the resonance occur at the design wave period, as follow

$$
k_{s}=m_{2}\left(\frac{2 \pi}{T_{\text {des }}}\right)^{2}
$$

where $T_{d e s}$ is the design wave period.

\subsubsection{Electromagnetic force coefficient}

If the circuit consists of a tightly-wound $\mathrm{N}$-turn coil of wires, the induced voltage, $e$, is given by

$$
e=-N \frac{d \Phi}{d t}
$$

where $\Phi$ is the magnetic flux. Then, Eq. (10) can be expressed as

$$
e=-N\left(\frac{\partial \Phi}{\partial i} \cdot \frac{d i}{d t}+\frac{\partial \Phi}{\partial x_{r}} \cdot \frac{d x_{r}}{d t}\right)
$$


Finally, Eq. (11) can be simplified as

$$
e=k_{e m} \dot{x}_{r}
$$

where $\dot{x}_{r}$ is relative velocity, $k_{e m}$ is the electromagnetic force coefficient, which is determined by the permanent magnet and the geometric parameters of the generator [23]. In addition, the electromagnetic force can be obtained according to Faraday's law

$$
F_{e m}=k_{e m} i
$$

In this study, the electromagnetic force coefficient, $k_{e m}$, is determined by simulation. The Ansoft Maxwell package has been used to construct a finite element model of the linear generator. The no-load induced voltages and the magnetic field distributions and their variations have been simulated under different velocity movements of the permanent magnet. The finite element method (FEM) is used to solve Maxwell's equations.

The no-load induced voltage under different permanent magnet velocity is shown in Fig. 6. It can be seen that the induced voltages of the generator are nearly sinusoidal. Fig. 7 shows the variation of the magnetic-field lines in one cycle for the case when $\dot{x}=0.5 \cos (0.8976 t)$. Then, the simulated data of the no-load induced voltages are handled by the least squares fitting method, and the values of the electromagnetic force coefficient, $k_{e m}$, are calculated.

Table 2 shows the simulation results of the electromagnetic force coefficient. As shown in Table 2, the simulation results of the electromagnetic force coefficient under different permanent magnet velocities have little difference and the average value is about 200 N/A, which is used in the later analysis. 


\section{Mathematical model}

\subsection{Dynamics model}

For waves in deep water, the linear wave theory developed by Airy (1845) can be applied [24]. The wave elevation in a fixed position is as follow

$$
\eta=a \cos (\omega t)=\frac{H}{2} \cos (\omega t)
$$

where $a$ is the wave amplitude and $H$ is the wave height.

From the above, $R A O$ is set to 1 . That is, the displacement of the floating body is the same as that of the wave,

$$
x_{1}=\frac{H}{2} \cos (\omega t)
$$

Then, the system can be simplified to a forced vibration of the inner body under harmonic excitation as seen in Fig. 8. When a body is subjected to harmonic excitation, it is forced to vibrate at the same frequency as that of the excitation. The displacement of the inner body is denoted by $x_{2}$. It is modeled by

$$
m_{2} \ddot{x}_{2}=F_{e m}+F_{s}
$$

where the force is a sum of the electromagnetic force, $F_{e m}=-k_{e m} i$, and the mechanical spring forces, $F_{s}=-k_{s}\left(x_{2}-x_{1}\right)$.

Whereas in this study, we only concern the relative displacement between the inner body and the floating body. It is denoted by $x_{r}$

$$
x_{r}=x_{2}-x_{1}
$$

Then, Eq. (16) can be rewritten as

$$
m_{2} \ddot{x}_{r}+k_{s} x_{r}+k_{e m} i+m_{2} \ddot{x}_{1}=0
$$




\subsection{Electromagnetics model}

The load to connect the generator is assumed as a purely resistive load. As shown in Fig. 9, $e$ is the induced voltage, $i$ is the current in the circuit, $R_{g}$ is the generator resistance, $L_{g}$ is the generator inductance and $R_{l}$ is the load resistance.

According to Kirchhoff's Voltage Law (KVL), the circuit equation can be expressed as

$$
e=\left(R_{g}+R_{l}\right) i+L_{g} \frac{d i}{d t}
$$

According to Eq. (12), Eq. (19) can be described as

$$
k_{e m} \dot{x}_{r}=\left(R_{g}+R_{l}\right) i+L_{g} \dot{i}
$$

\subsection{Solution of the coupled model}

To sum up, the whole governing equations of the system are as follows

$$
\left\{\begin{array}{l}
x_{1}=\frac{H}{2} \cos (\omega t) \\
m_{2} \ddot{x}_{r}+k_{s} x_{r}+k_{e m} i+m_{2} \ddot{x}_{1}=0 \\
k_{e m} \dot{x}_{r}-\left(R_{g}+R_{l}\right) i-L_{g} \dot{i}=0
\end{array}\right.
$$

The solution to these equations consists of two parts, the complementary function, which is the solution of the homogeneous equation, and the particular integral. The complementary function, in this case, is a damped free vibration. However, the particular solution is a steady-state oscillation of the same frequency $\omega$ as that of the excitation. We can assume the particular solution to be of the form

$$
\begin{gathered}
x_{r}=X_{m} \cos \left(\omega t+\varphi_{x}\right) \\
i=I_{m} \cos \left(\omega t+\varphi_{i}\right)
\end{gathered}
$$

where $X_{m}$ is the amplitude of the relative displacement, $\varphi_{x}$ is the phase of the relative displacement with respect to the excitation, $I_{m}$ is the amplitude of the current, and $\varphi_{i}$ is 
the phase of the current with respect to the excitation.

Remembering that in harmonic motion the phases of the velocity and acceleration are ahead of the displacement by $\pi / 2$ and $\pi$, respectively, the terms of the differential equations can be displayed graphically, as in Fig. 10(a) and (b). The amplitudes and phases of the relative displacement and current are found by substituting Eq. (21) and (22) into the differential equations. Finally, the theoretical solution is obtained as follows

$$
\left\{\begin{array}{l}
X_{m}=\frac{m_{2} H \omega^{2} \sqrt{\left(R_{g}+R_{l}\right)^{2}+\left(\omega L_{g}\right)^{2}}}{2 \sqrt{\left[\left(k_{s}-m_{2} \omega^{2}\right)\left(R_{g}+R_{l}\right)\right]^{2}+\left[\omega k_{e m}{ }^{2}+\omega L_{g}\left(k_{s}-m_{2} \omega^{2}\right)\right]^{2}}} \\
\varphi_{x}=-\arctan \left[\frac{\omega k_{e m}{ }^{2}\left(R_{g}+R_{l}\right)}{\omega^{2} k_{e m}{ }^{2} L_{g}+\left(k_{s}-m_{2} \omega^{2}\right)\left[\left(R_{g}+R_{l}\right)^{2}+\left(\omega L_{g}\right)^{2}\right]}\right] \\
I_{m}=\frac{\omega k_{e m} X}{\sqrt{\left(R_{g}+R_{l}\right)^{2}+\left(\omega L_{g}\right)^{2}}} \\
\varphi_{i}=\varphi_{x}+\arctan \left(\frac{R_{g}+R_{l}}{\omega L_{g}}\right)
\end{array}\right.
$$

Then, the induced voltage can be expressed as

$$
e=k_{e m} \dot{x}_{r}=\omega k_{e m} X_{m} \cos \left(\omega t+\varphi_{x}+\frac{\pi}{2}\right)
$$

The phase difference between the induced voltage and the current can be calculated by

$$
\Delta \varphi=\varphi_{x}+\frac{\pi}{2}-\varphi_{i}=\arctan \left(\frac{\omega L_{g}}{R_{g}+R_{l}}\right)
$$

The relative motion transmissibility is introduced as

$$
T_{r}=\frac{X_{m}}{a}=\frac{m_{2} \omega^{2} \sqrt{\left(R_{g}+R_{l}\right)^{2}+\left(\omega L_{g}\right)^{2}}}{\sqrt{\left[\left(k_{s}-m_{2} \omega^{2}\right)\left(R_{g}+R_{l}\right)\right]^{2}+\left[\omega k_{e m}{ }^{2}+\omega L_{g}\left(k_{s}-m_{2} \omega^{2}\right)\right]^{2}}}
$$

The effective value of the current can be calculated by 


$$
I=I_{m} / \sqrt{2}=\frac{\omega k_{e m} X_{m}}{\sqrt{2\left[\left(R_{g}+R_{l}\right)^{2}+\left(\omega L_{g}\right)^{2}\right]}}
$$

The effective value of the induced voltage can be calculated by

$$
E=\omega k_{e m} X_{m} / \sqrt{2}
$$

The generated electrical real power can be calculated by

$$
\begin{aligned}
& P_{e}=E I \cos (\Delta \varphi) \\
& 8\left[m_{2}\left(\left(\frac{2 \pi}{T_{\text {des }}}\right)^{2}-\omega^{2}\right)\left(R_{g}+R_{l}\right)\right]^{2}+\left[\omega{k_{e m}}^{2}+m_{2} \omega L_{g}\left(\left(\frac{2 \pi}{T_{\text {des }}}\right)^{2}-\omega^{2}\right)\right]^{2}
\end{aligned}
$$

where $\cos (\triangle \varphi)$ is the power factor.

The ability of the WEC to extract power can be expressed by the power capture ratio,

$$
P_{r a t}=\frac{P_{e}}{D k_{w} H^{2} T}
$$

where $D$ is the diameter of the outer body and $k_{w} H^{2} T$ is the total time averaged wave power per meter wave front. Using the deep water approximation, the wave constant $k_{w}$ is given by $k_{w}=\rho g^{2} / 64 \pi$.

\section{Results and discussion}

\subsection{Performance under different load resistance}

Firstly, we discuss the cases under different load resistance. The wave height, $H$, and design wave period, $T_{d e s}$, are chosen to be $3 \mathrm{~m}$ and $7 \mathrm{~s}$, which are the average wave height and most common wave period in the Fukue Island [22].

The phase difference between the induced voltage and the current, $\Delta \varphi$, has an impact on the character of the electromagnetic force, $F_{\text {em }}$. As seen in Fig. 10(a), when 
the phase difference equals to 0 , the electromagnetic force has the same phase angle with the relative velocity, $\dot{x}_{r}$. Consequently, the electromagnetic force may be seen as a pure damping force. Whereas, when the phase difference is not equal to 0 , only a component of the electromagnetic force, which is parallel to vector $\dot{x}_{r}$, may be seen as pure damping force. Whereas, the other component of the electromagnetic force, which is parallel to vector $x_{r}$, should be added to the spring force. The variation of the phase difference with wave period for different load resistance is shown in Fig. 11. It can be seen that the phase difference is nearly 0 within the wave period range for all the cases, indicating that the electromagnetic force may be approximately seen as a pure damping force.

Fig. 12(a) presents the variation of the relative motion transmissibility, $T_{r}$, with wave period, $T$, for different load resistance. These curves show that the load resistance has a large influence on the vibration response of the system. For a given wave period, the relative motion transmissibility of higher load resistance case is larger than that of lower load resistance case, reflecting that the relative displacement of higher load resistance case is also higher. This is because the higher load resistance introduces a lower current, as shown in Fig. 12(b), and thereby a smaller electromagnetic force, which may be approximately seen as a smaller damping force. It's worth noting that a clearly resonance occurs at the wave period of $6.5 \mathrm{~s}$ with the load resistance of $10 \Omega$ and the wave period of $4.7 \mathrm{~s}$ with the load resistance of $4.9 \Omega$. The difference of the wave periods where resonance occurs is due to that the damping force has the ability to change the resonance frequency. When the system is subjected to higher damping force, the resonance frequency is shifted towards lower wave period. For the cases with the load resistances of $0.5 \Omega$ and $2.2 \Omega$, no resonance is visible since the resonant peak is 
outside the wave period range. In addition, the relative motion transmissibility is great than 1 within large wave period ranges (throughout the range with the load resistance of $10 \Omega$ and $4 \sim 6.6 \mathrm{~s}$ with the load resistance of $4.9 \Omega$ ), indicating that the amplitude of the relative displacement is increased compared to that of the wave.

The variation of the effective value of the current, $I$, with wave period, $T$, for different load resistance is shown in Fig. 12(b). It can be seen that the effective value of the current decreases with a rise in wave period. For a given wave period, the case with a higher load resistance would introduce a lower effective value of current, except wave period of $7 \mathrm{~s}$, at which the effective value of the current for all the cases are the same. This phenomenon is caused by the fact that the inner body's nature frequency of undamped oscillation is designed to match the wave frequency, i.e., $k_{s}=m_{2} \omega^{2}$, at wave period of $7 \mathrm{~s}$. Then, it can be easily explained with Fig. 10(a) or Eq. (23). If $k_{s}=m_{2} \omega^{2}$, the length of the vector $k_{s} x_{r}$ is equal to that of the vector $m_{2} \ddot{x}_{r}$. Therefore, the length of the vector $k_{e m} i$ should be also equal to that of the vector $m_{2} \ddot{x}_{1}$. That is, at wave period of $7 \mathrm{~s}, I_{m}=m_{2} H \omega^{2} / 2 k_{e m}$.

The variation of the effective value of the induced voltage, $E$, with wave period, $T$, for different load resistance is shown in Fig. 12(c). From the above, the induced voltage, $e$, is proportional to the relative velocity, $\dot{x}_{r}$, reflecting that the variation of the effective value of the induced voltage is determined by the wave frequency, $\omega$, and the amplitude of the relative displacement, $X_{m}$. The wave frequency decreases with a rise in wave period, and the variation of the amplitude of the relative displacement is similar to the relative motion transmissibility. The comprehensive effect of the wave frequency and the amplitude of the relative displacement makes the effective value of the induced voltage decrease with a rise in wave period. In addition, for a given wave 
period, similar to the relative motion transmissibility, the effective value of the induced voltage of higher load resistance case is larger than that of lower load resistance case. What's more, when the load resistance is $10 \Omega$, it can be clearly seen that the effective value of the induced voltage decreases slowly with the help of resonance than that of the other cases.

A more suitable system is expected to have a high power production coincides with a high power capture ratio. Fig. 13(a) and (b) show the variations of the generated electrical real power, $P_{e}$, and the corresponding power capture ratio, $P_{r a t}$, with wave period, $T$, for different load resistance. Their variations are similar. For the cases with lower load resistances $(0.5,2.2$, and $4.9 \Omega)$, in which the resonance is slight or absent, the generated electrical real power and the corresponding power capture ratio decrease quite rapidly with wave period increasing. In addition, for a given wave period, the generated electrical real power and the corresponding power capture ratio of higher load resistance case are higher.

However, for the case with a higher load resistance $(10 \Omega)$, in which the resonance is intense, the generated electrical real power and the corresponding power capture ratio are significant high within a large wave period range and decrease slowly with the help of resonance in the system. Within the wave period range of $4 \sim 7 \mathrm{~s}$, the generated electrical real power shows a steady decrease from $19.5 \mathrm{~kW}$ to $1.02 \mathrm{~kW}$, and the corresponding power capture ratio shows a steady decrease from $22.7 \%$ to $0.5 \%$. Moreover, the power capture ratio of the system has been compared to that of the single-body heaving system [25], as shown in Fig. 13(b). It can be seen that the fully floating system can introduce a similar power capture ratio compared to the single-body heaving system. 


\subsection{Effect of wave height}

The wave height can affect the power production of the system. This section presents the effect of the wave height on the performance of the system with the load resistance of $10 \Omega$ as an example.

The variations of the generated electrical real power, $P_{e}$, and the corresponding power capture ratio, $P_{r a t}$, with wave period, $T$, for different wave height are shown in Fig. 14(a) and (b). As shown in Fig. 14(a), the wave height has a large influence on the power production. For a given wave period, the system can generate more electrical real power for the case with a higher wave height. For example, the system can generate as high as $54.1 \mathrm{~kW}$ electrical real power for the case with the wave height of 5 m. A more interesting thing is that the power capture ratio will not be affected by the wave height, i.e., the power capture ratios for the cases with different wave height are the same, as shown in Fig. 14(b). It can be explained with Eq. (29) and (30). The wave height, $H$, will not appear in the function of power capture ratio, $P_{r a t}$.

\subsection{Effect of spring constant}

The spring constant can affect the ability of the system to absorb energy. From Eq. (9), the spring constant is determined by the design wave period, as shown in Fig. 15. This section presents the effect of the spring constant on the performance of the system with the load resistance of $10 \Omega$ as an example.

Fig. 16(a) and (b) show the variations of the generated electrical real power, $P_{e}$, and the corresponding power capture ratio, $P_{r a t}$, with wave period, $T$, for different spring constant. As shown in Fig. 16(a) and (b), the variations of the generated electrical real power and the corresponding power capture ratio are similar. When the wave period is 
small, the case with larger spring constant can introduce significant higher electrical real power and power capture ratio. For example, the case with the highest spring constant, i.e., $12633 \mathrm{~N} / \mathrm{m}$, has a maximum generated electrical real power of $54.9 \mathrm{~kW}$ and a maximum power capture ratio of $57 \%$. However, with the wave period increasing, the electrical real power and power capture ratio of the larger spring constant case will decrease more rapidly. Then, when the wave period increases to a big value, the electrical real power and power capture ratio of the larger spring constant case will become lower conversely. It's worth noting that the resonance in the larger spring constant case is more obvious. Moreover, the resonance frequencies for different spring constant cases are different, which can be explained by that the spring constant has the ability to change the inner body's nature frequency. When the system is subjected to higher spring constant, the resonance frequency is shifted towards lower wave period. Thus, by selecting a suitable spring constant, the system can be tuned to have a natural period of oscillation that coincides with the sea state.

\section{Conclusions}

In order to reduce the problems in the traditional WECs with direct-driven linear generators, a novel WEC is proposed in this paper. In this system, the problems associated with mooring and maintenance have been largely decreased. The seawater corrosion can also be neglected. A coupled model of the dynamics of the wave, the floating body and the inner body and the electromagnetic characteristics of the direct-driven linear generator has been described to analyze its ability. A nearly sinusoidal voltage has been induced in the generator. When the load resistance is $10 \Omega$, with the help of resonance, the generated electrical real power shows a steady decrease 
from $19.5 \mathrm{~kW}$ to $1.02 \mathrm{~kW}$, and the corresponding power capture ratio shows a steady decrease from $22.7 \%$ to $0.5 \%$ within the wave period range of $4 \sim 7 \mathrm{~s}$. The wave height can make a great influence on the generated electrical real power. Whereas, the power capture ratio will not be affected by the wave height. A resonance has been achieved in the case with the highest spring constant, i.e., $12633 \mathrm{~N} / \mathrm{m}$, with a maximum power capture ratio of $57 \%$, and with a decrease in spring constant, the resonance remains but with a lower amplitude response that decreases the power capture ratio, indicating the importance of spring constant. By selecting a suitable spring constant, the system can be tuned to have a natural period of oscillation that coincides with the sea state.

Future work will be focused on both experiments and simulations to validate the theoretical solution.

\section{Acknowledgement}

The authors gratefully acknowledge the support from Key International Program of Chinese Academy of Sciences (CAS-DOE, 1A1111KYSB20150014).

\section{References}

[1] Veigas M, López M, Iglesias G. Assessing the optimal location for a shoreline wave energy converter. Appl Energy 2014;132:404-411.

[2] Mohamed MH, Janiga G, Pap E, Thévenin D. Multi-objective optimization of the airfoil shape of Wells turbine used for wave energy conversion. Energy 2011;36(1): 438-446.

[3] López I, Pereiras B, Castro F, Iglesias G. Optimisation of turbine-induced damping for an OWC wave energy converter using a RANS-VOF numerical model. Appl Energy 2014;127:105-114. 
[4] Ramadan A, Mohamed MH, Abdien SM, Marzouk SY, Feky AE, Baz ARE. Analytical investigation and experimental validation of an inverted cup float used for wave energy conversion. Energy 2014;70:539-546.

[5] Pinson P, Reikard G, Bidlot JR. Probabilistic forecasting of the wave energy flux. Appl Energy 2012;93:364-370.

[6] Harne RL, Schoemaker ME, Dussault BE, Wang KW. Wave heave energy conversion using modular multistability. Appl Energy 2014;130:148-156.

[7] Longo S, Chiapponi L, Liang D. Analytical study of the water surface fluctuations induced by grid-stirred turbulence. Appl math model 2013;37(12):7206-7222.

[8] Thorpe TW. A brief review of wave energy. London, UK: Harwell Laboratory, Energy Technology Support Unit, 1999.

[9] Yemm R, Henderson R, Taylor C. The OPD pelamis WEC: current status and onward programme. In: Proceedings of 4th European wave energy conference. Alborg Denmark; 2000.

[10] Heath T, Whittaker TJT, Boake CB. The design, construction and operation of the LIMPET wave energy converter (Islay, Scotland). In: Proceedings of 4th European wave energy conference. Alborg Denmark; 2000.

[11]Baker NJ, Mueller MA. Direct drive wave energy converters. Revue des Energies Renouvelables 2001;4(2):1-7.

[12]Chiba S, Waki M, Wada T, Hirakawa Y, Masuda K, Ikoma T. Consistent ocean wave energy harvesting using electroactive polymer (dielectric elastomer) artificial muscle generators. Appl Energy 2013;104:497-502.

[13] Drew B, Plummer AR, Sahinkaya MN. A review of wave energy converter technology. Proc Inst Mech Eng, Part A: J Power Energy 2009;223(8):887-902. 
[14] Mueller MA. Electrical generators for direct drive wave energy converters. IEE Proc Generation Trans Distrib 2002;149(4):446-456.

[15]Falcão AF de O. Wave energy utilization: A review of the technologies. Renew Sustain Energy Rev 2010;14(3):899-918.

[16] Gardner FE. Learning experience of AWS pilot plant test offshore Portugal. In: Proceedings of 6th European wave energy conference; 2005. p. 149-54.

[17] Waters R, Stålberg M, Danielsson O, Svensson O, Gustafsson S, Strömstedt E, Eriksson M, Sundberg J, Leijon M . Experimental results from sea trials of an offshore wave energy system. Appl Phys Lett 2007;90(3):034105.

[18]Falnes J. Wave-energy conversion through relative motion between two single-mode oscillating bodies. J Offshore Mech Arctic Eng 1999;121(1):32-38.

[19]Redlich RW. Electromechanical transducer particularly suitable for a linear alternator driven by a free-piston Stirling engine: U.S. Patent 4,602,174. 1986-7-22.

[20] Stoker J. Water waves: the mathematical theory with applications. New York: Interscience Publishers, Inc; 1957.

[21]Falnes J. Ocean waves and oscillating systems. Cambridge University Press, 2002.

[22]Zheng CW, Zhou L, Jia BK, Pan J, Li X. Wave characteristic analysis and wave energy resource evaluation in the China Sea. J Renew Sustain Energy 2014;6(4):043101.

[23]Feng HH, Song Y, Zuo ZX, Shang J, Wang YD, Roskilly T. Stable Operation and Electricity Generating Characteristics of a Single-Cylinder Free Piston Engine Linear Generator: Simulation and Experiments. Energies 2015;8(2):765-785.

[24]McCormick ME. Ocean engineering mechanics: with applications. Cambridge 
University Press, 2009.

[25]Engström J, Kurupath V, Isberg J, Leijon M. A resonant two body system for a point absorbing wave energy converter with direct-driven linear generator. J Appl Phys 2011;110(12):124904. 
Table Captions

Table 1. Design parameters.

Table 2. Simulation results of electromagnetic force coefficient. 


\section{Figure Captions}

Fig. 1. A schematic of the AWS.

Fig. 2. A schematic of the single body heaving system.

Fig. 3. The conceptual schematic of the novel WEC.

Fig. 4. A typical RAO curve.

Fig. 5. Parameterized geometry of the generator.

Fig. 6. No-load induced voltage under different permanent magnet velocity.

Fig. 7. Variation of magnetic-field lines in one cycle.

Fig. 8. The simplified dynamics model.

Fig. 9. The electromagnetics model.

Fig. 10. Phasor diagram of dynamics model (a) and electromagnetics model (b).

Fig. 11. Variation of phase difference $\Delta \varphi$ between induced voltage and current with wave period $T$.

Fig. 12. Variation of relative motion transmissibility $T_{r}$ (a), effective value of current $I$

(b) and effective value of induced voltage $E$ (c) with wave period $T$.

Fig. 13. Variations of generated electrical real power $P_{e}(a)$ and power capture ratio $P_{\text {rat }}$

(b) with wave period $T$ for different load resistance

Fig. 14. Variations of generated electrical real power $P_{e}(a)$ and power capture ratio $P_{\text {rat }}$

(b) with wave period $T$ for different wave height

Fig. 15. Variation of spring constant $k_{s}$ with design wave period $T_{\text {des }}$

Fig. 16. Variations of generated electrical real power $P_{e}(a)$ and power capture ratio $P_{\text {rat }}$

(b) with wave period $T$ for different spring constant 
Table 1 Design parameters

\begin{tabular}{ccc}
\hline $\begin{array}{c}\text { Diameter of outer body } \\
\text { Mass of inner body }\end{array}$ & $D$ & $5 \mathrm{~m}$ \\
Coil turns & $m_{\text {in }}$ & $8 \mathrm{ton}$ \\
Air gap 1 & $\mathrm{N}$ & 50 \\
Air gap 2 & $g_{1}$ & $3 \mathrm{~mm}$ \\
Length of the air gap & $g_{2}$ & $3 \mathrm{~mm}$ \\
Diameter of the air gap 1 & $2(s+l)$ & $2.6 \mathrm{~m}$ \\
Diameter of the air gap 2 & $D_{1}$ & $1.203 \mathrm{~m}$ \\
Diameter of the permanent magnet & $D_{2}$ & $1.409 \mathrm{~m}$ \\
Permanent magnet material & $\mathrm{NdFe}$ & $1.306 \mathrm{~m}$ \\
Generator resistance & $R_{g}$ & Length:1.3 m Thickness:0.1 m \\
Generator inductance & $L_{g}$ & $0.44 \Omega$ \\
Load resistance & $R_{l}$ & $11.7 \mathrm{mH}$ \\
\hline
\end{tabular}


Table 2 Simulation results of electromagnetic force coefficient

\begin{tabular}{cc}
\hline$\dot{x}_{r}(\mathrm{~m} / \mathrm{s})$ & $k_{e m}(\mathrm{~N} / \mathrm{A})$ \\
\hline $0.1 \cos (0.8976 t)$ & 199.8 \\
$0.2 \cos (0.8976 t)$ & 199.9 \\
$0.3 \cos (0.8976 t)$ & 200.0 \\
$0.4 \cos (0.8976 t)$ & 200.2 \\
$0.5 \cos (0.8976 t)$ & 200.4 \\
\hline
\end{tabular}




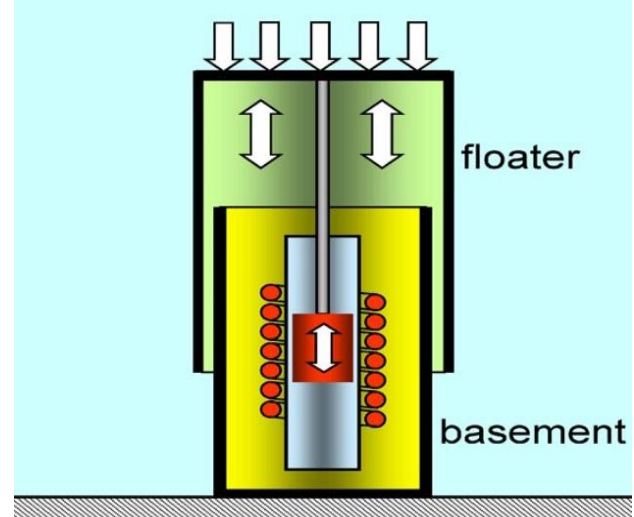

Fig. 1. A schematic of the AWS [15] 


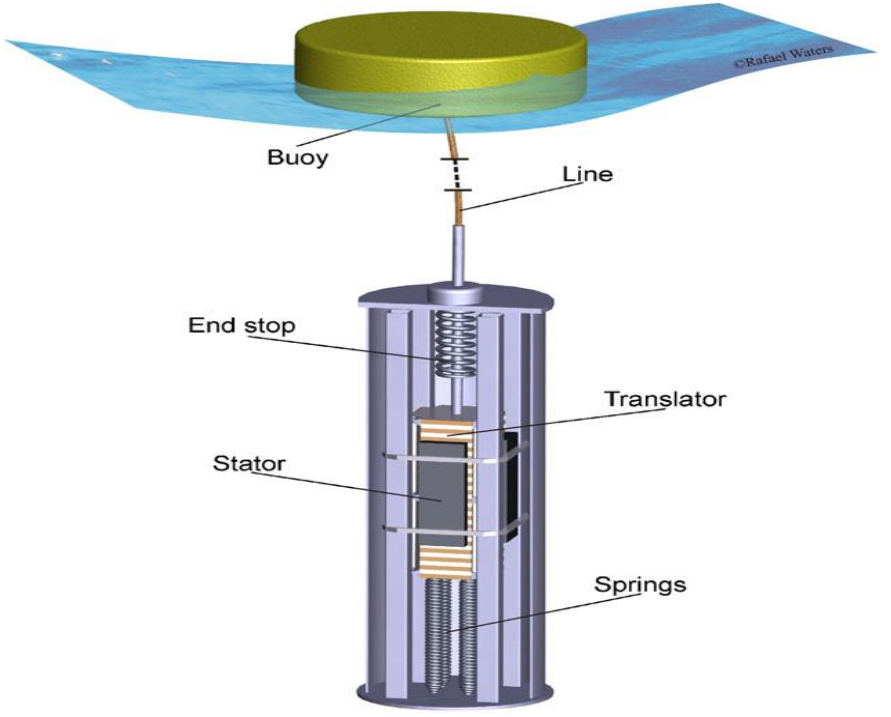

Fig. 2. A schematic of the single body heaving system [17] 


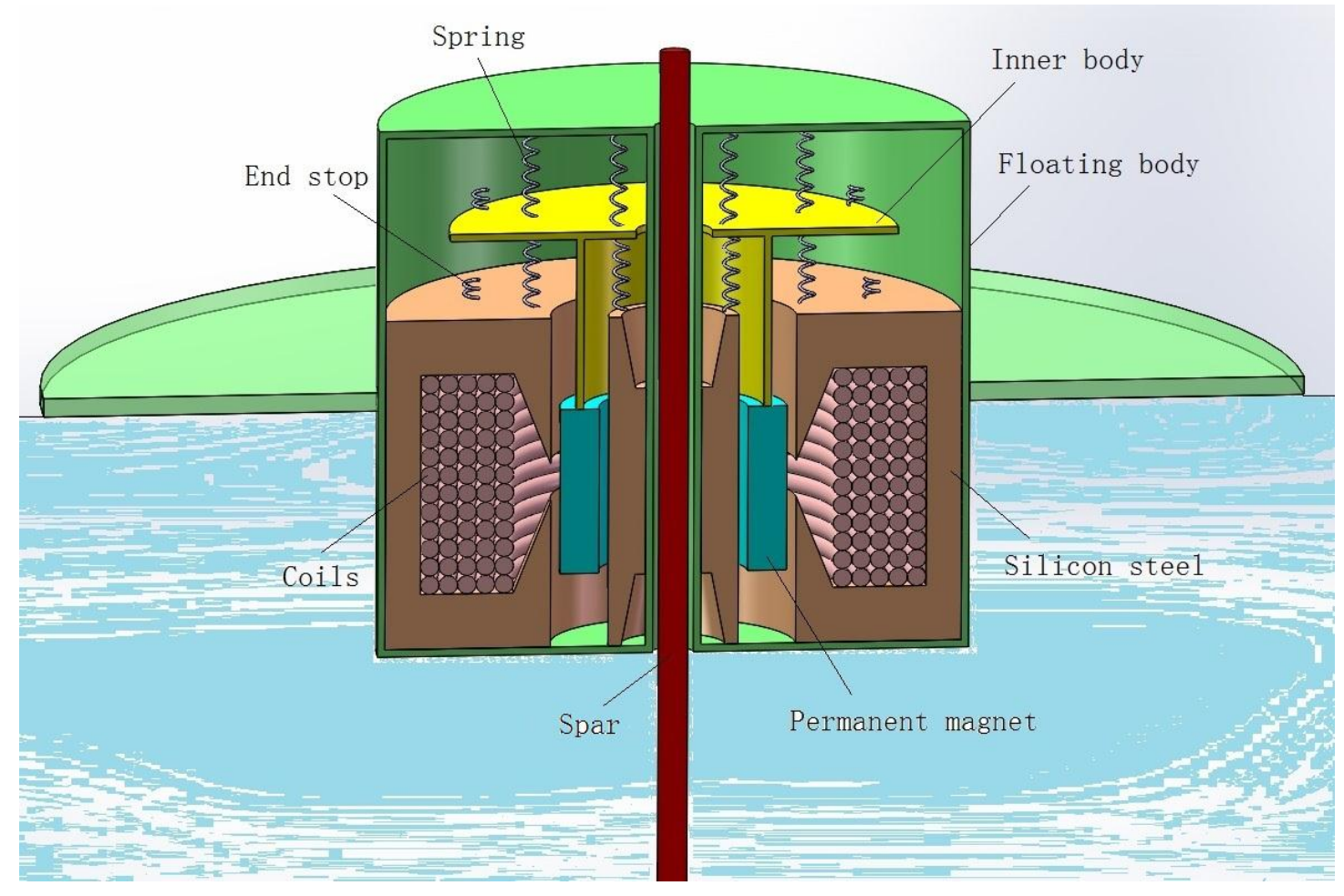

Fig. 3. The conceptual schematic of the novel WEC 


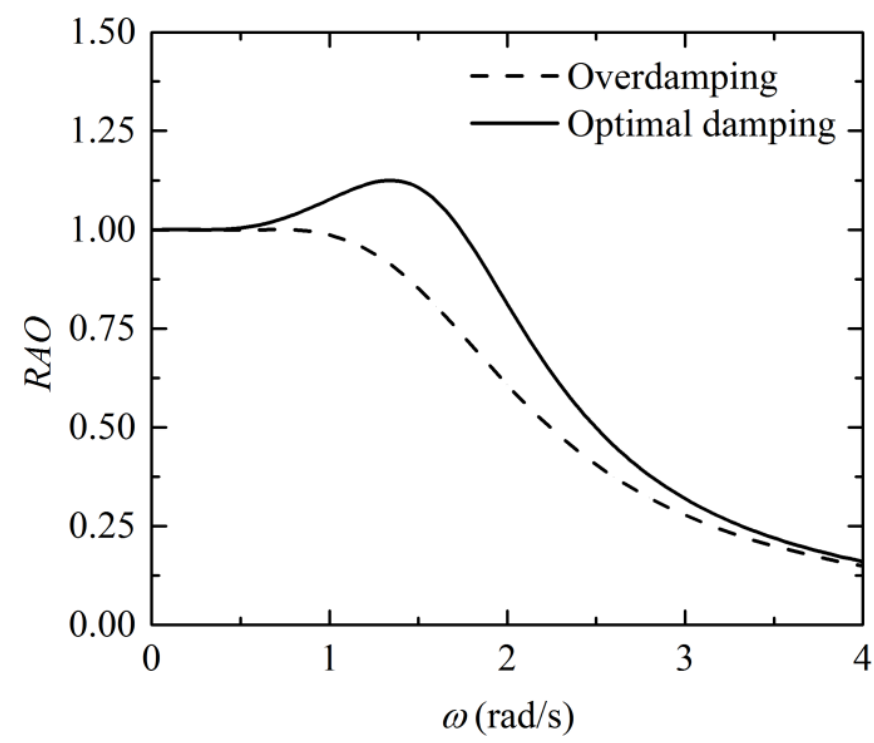

Fig. 4. A typical $R A O$ curve 


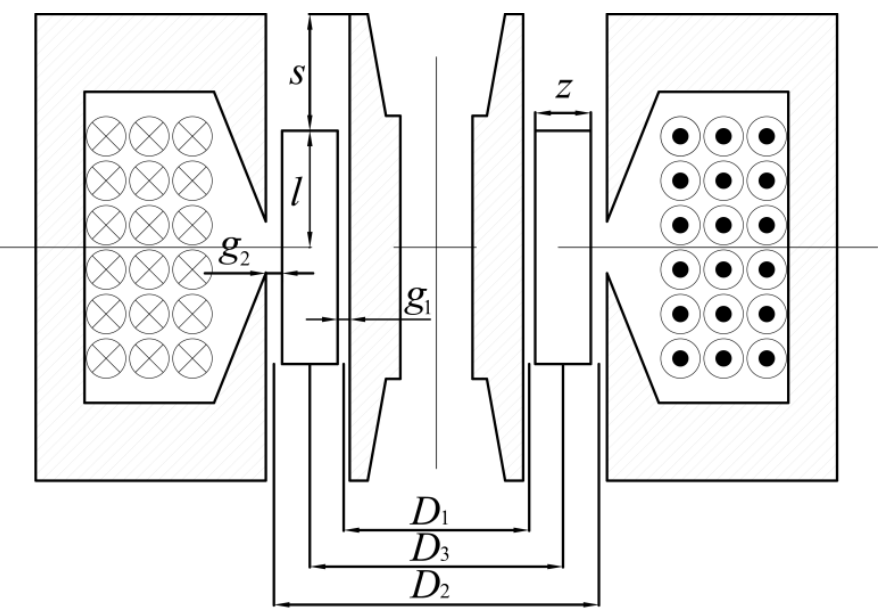

Fig. 5. Parameterized geometry of the generator 


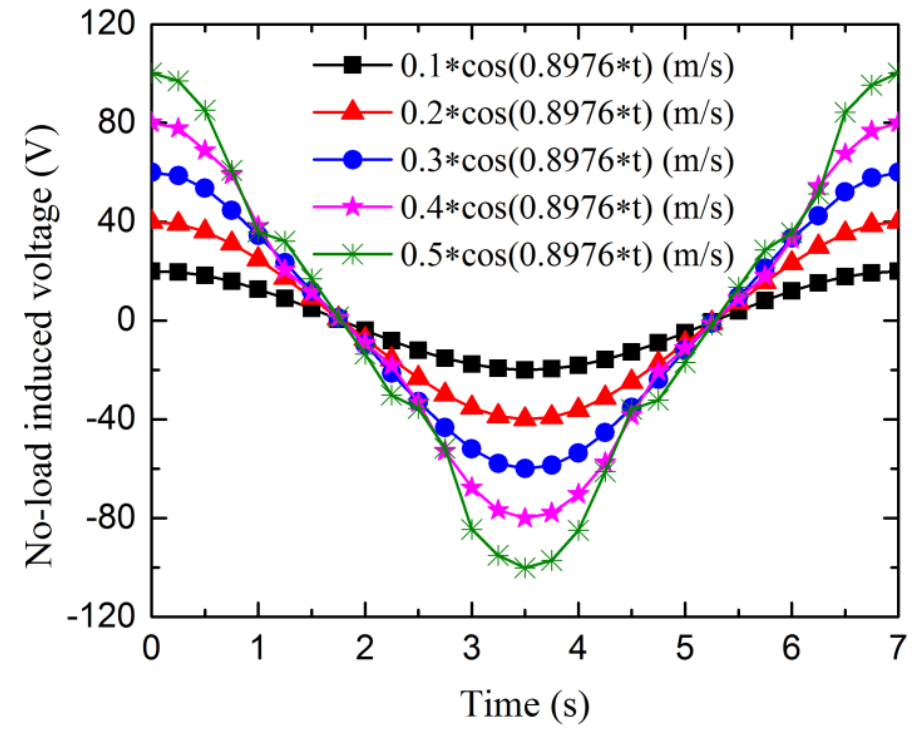

Fig. 6. No-load induced voltage under different permanent magnet velocity 


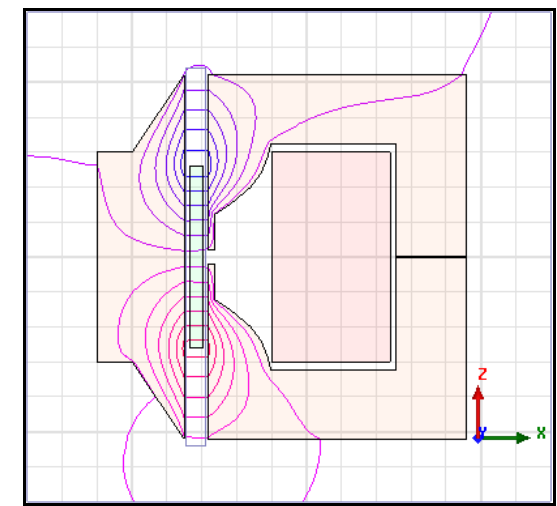

(a)

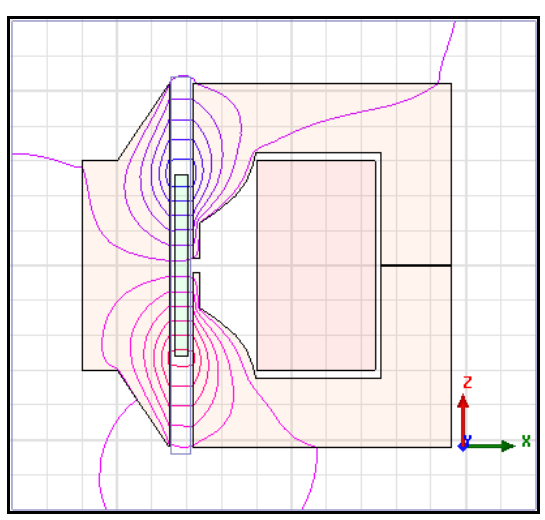

(c)

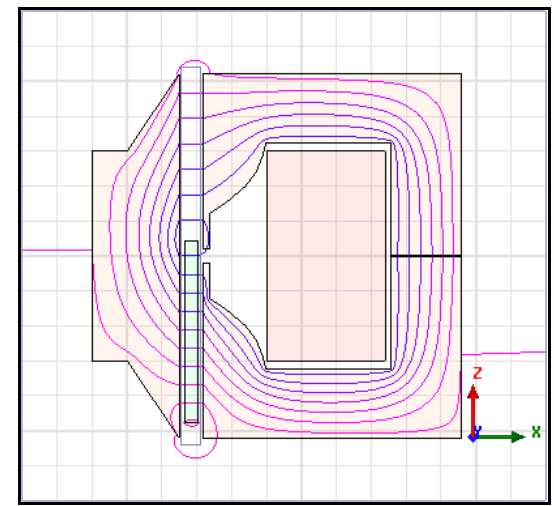

(b)

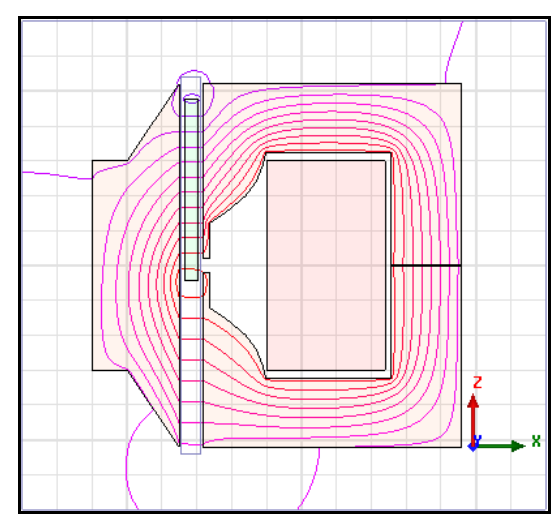

(d)

Fig. 7. Variation of magnetic-field lines in one cycle
(a) 0 and $7 \mathrm{~s}$
(b) $1.75 \mathrm{~s}$
(c) $3.5 \mathrm{~s}$
(d) $5.25 \mathrm{~s}$ 


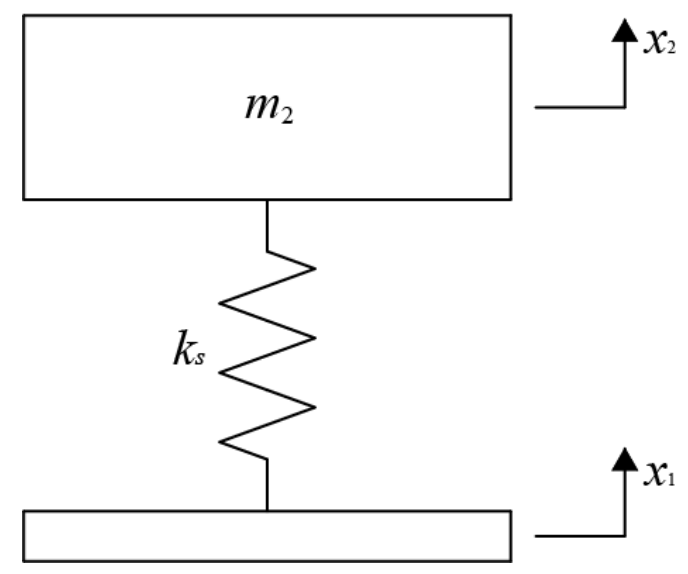

Fig. 8. The simplified dynamics model 


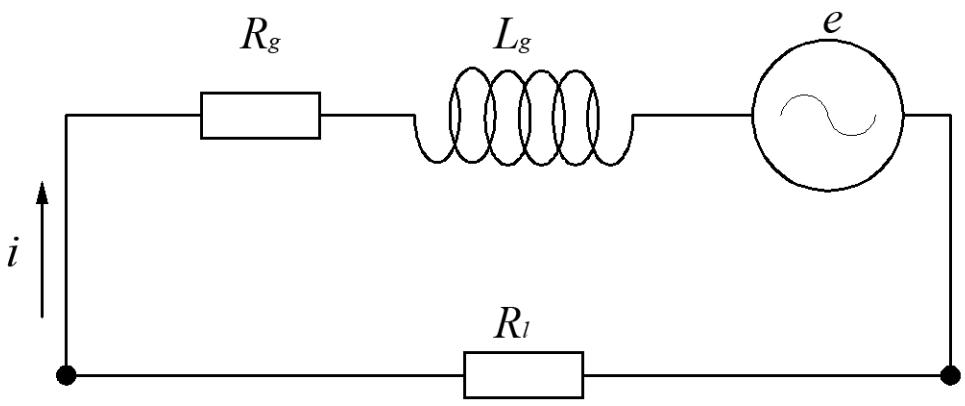

Fig. 9. The electromagnetics model 


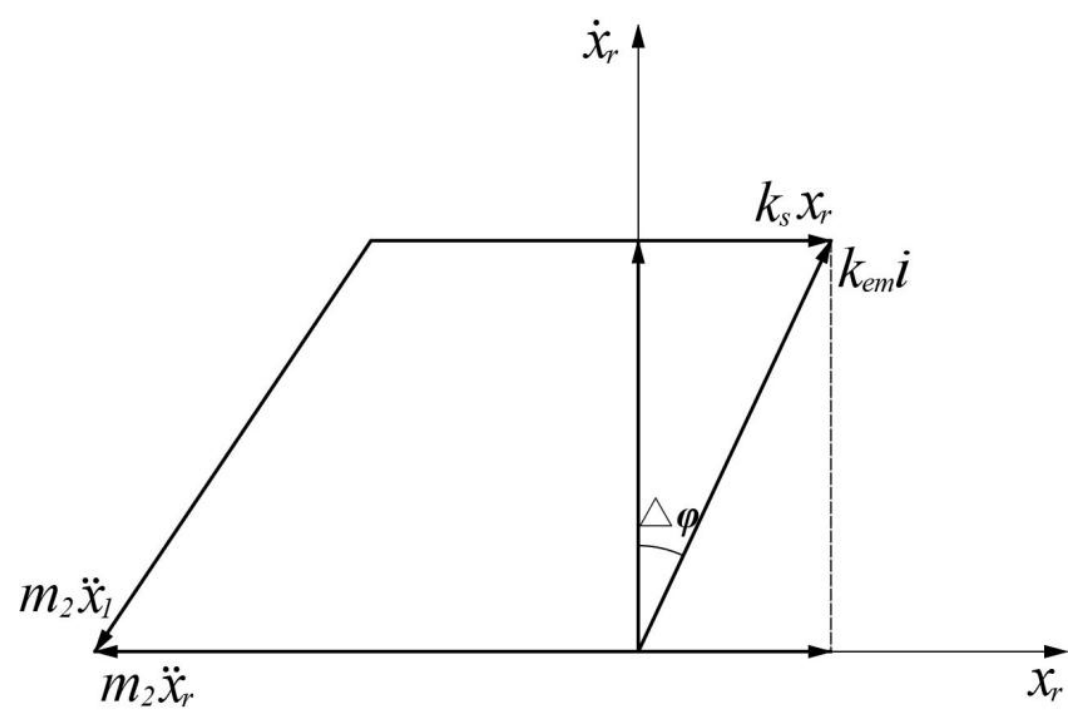

(a)

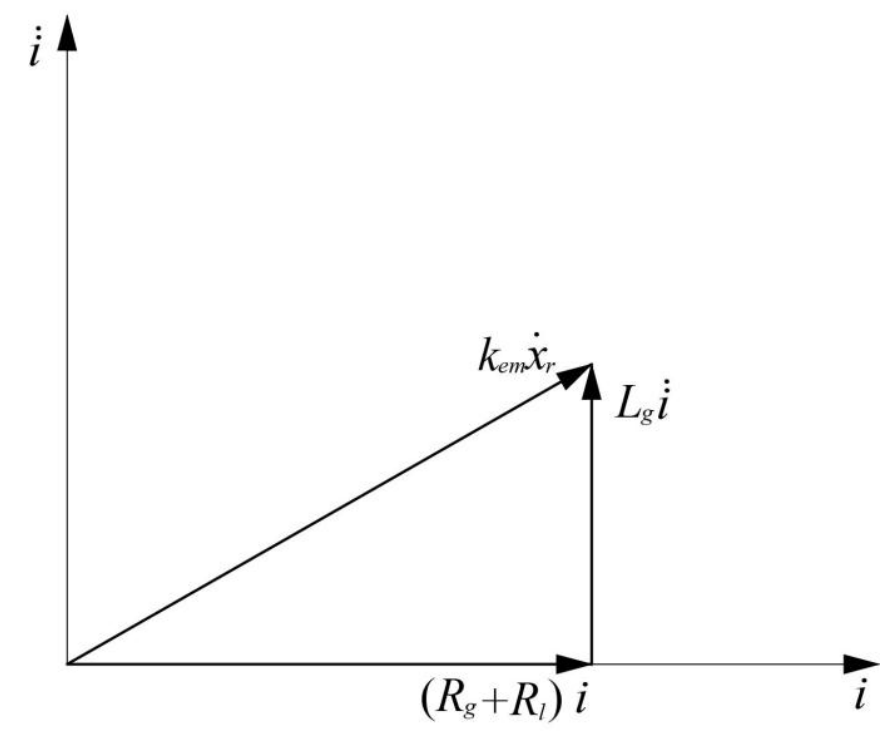

(b)

Fig. 10. Phasor diagram of dynamics model (a) and electromagnetics model (b) 


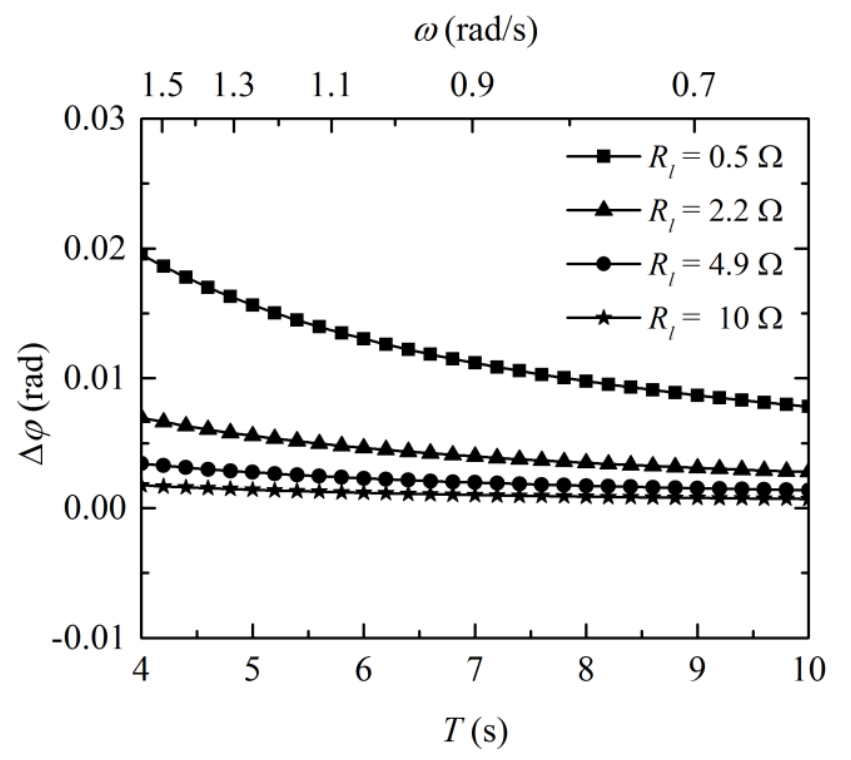

Fig. 11. Variation of phase difference $\Delta \varphi$ between induced voltage and current with wave period $T$ 


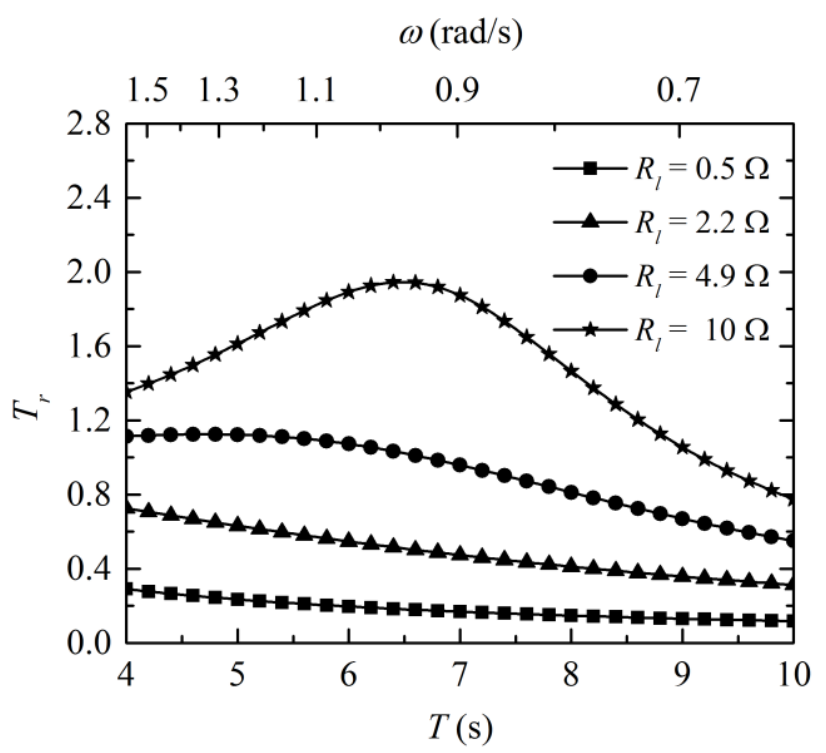

(a)

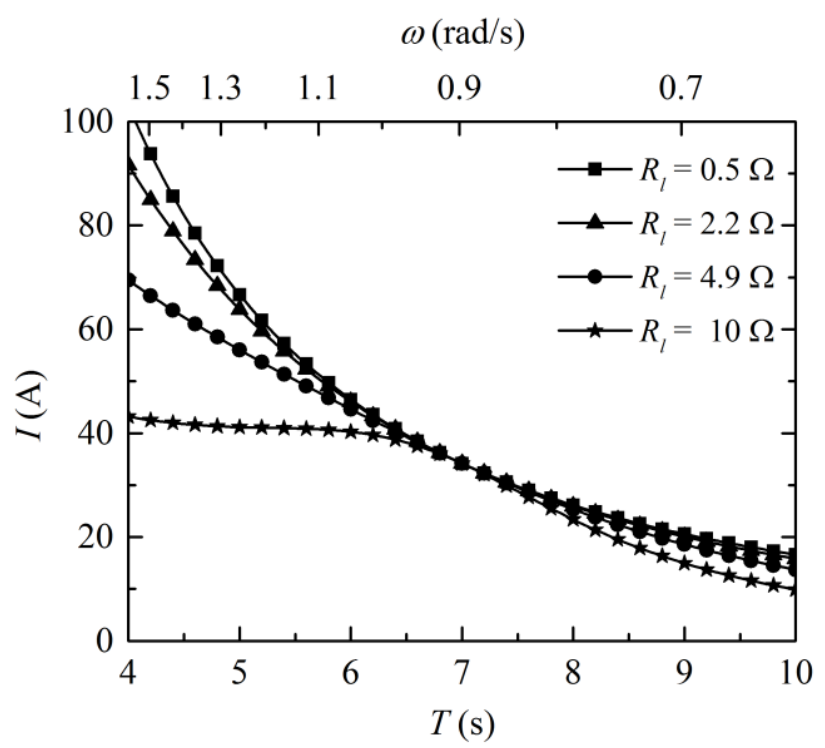

(b) 


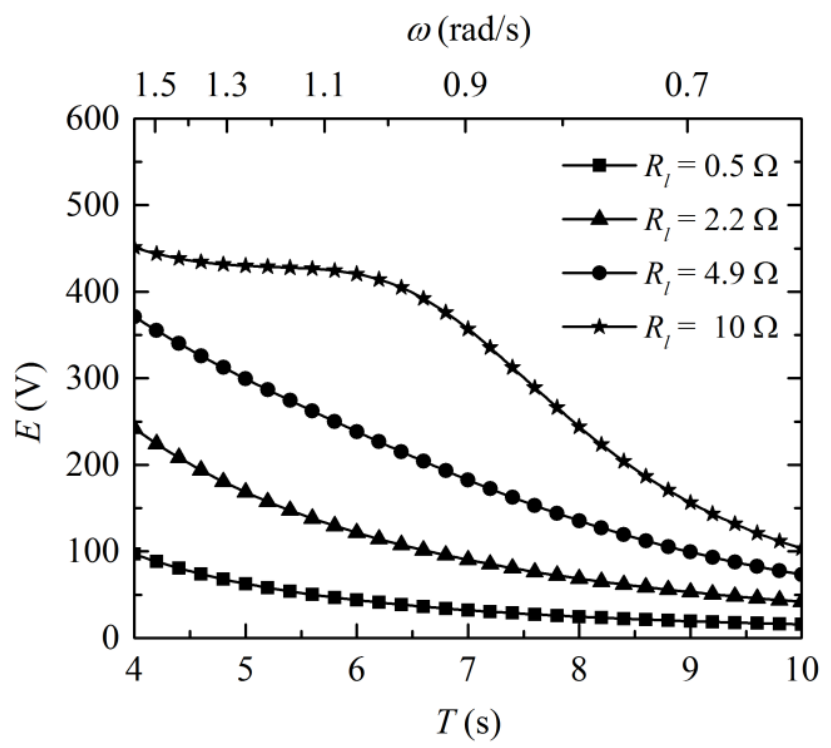

(c)

Fig. 12. Variations of relative motion transmissibility $T_{r}$ (a), effective value of current $I$

(b) and effective value of induced voltage $E$ (c) with wave period $T$ 


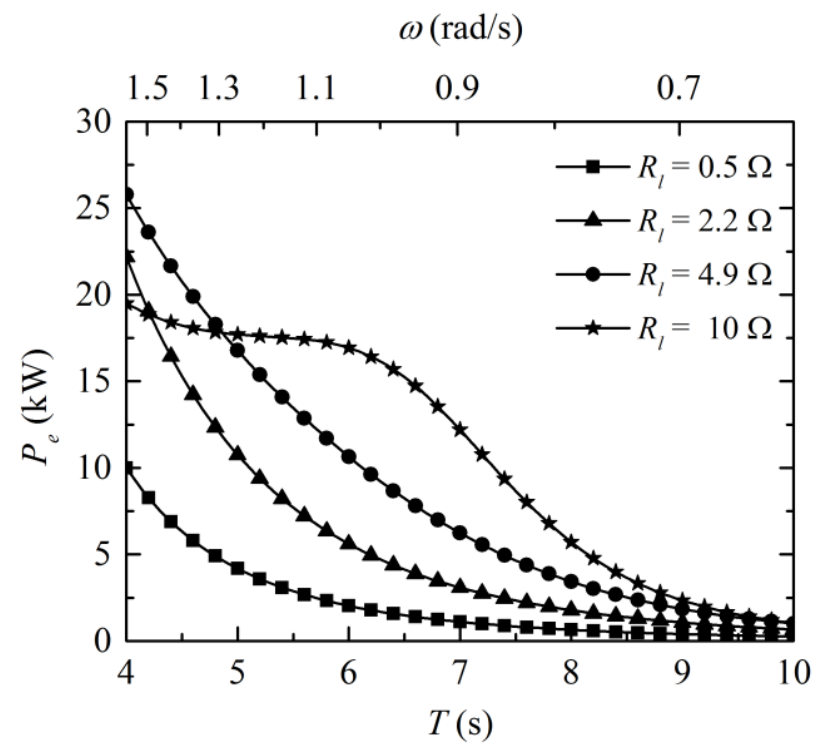

(a)

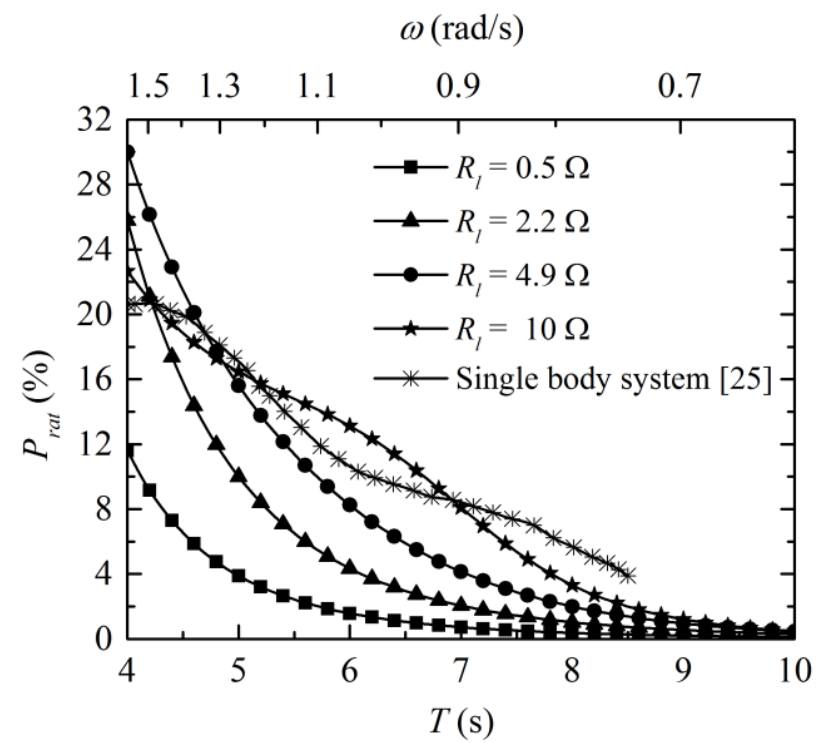

(b)

Fig. 13. Variations of generated electrical real power $P_{e}(\mathrm{a})$ and power capture ratio $P_{\text {rat }}$ (b) with wave period $T$ for different load resistance 


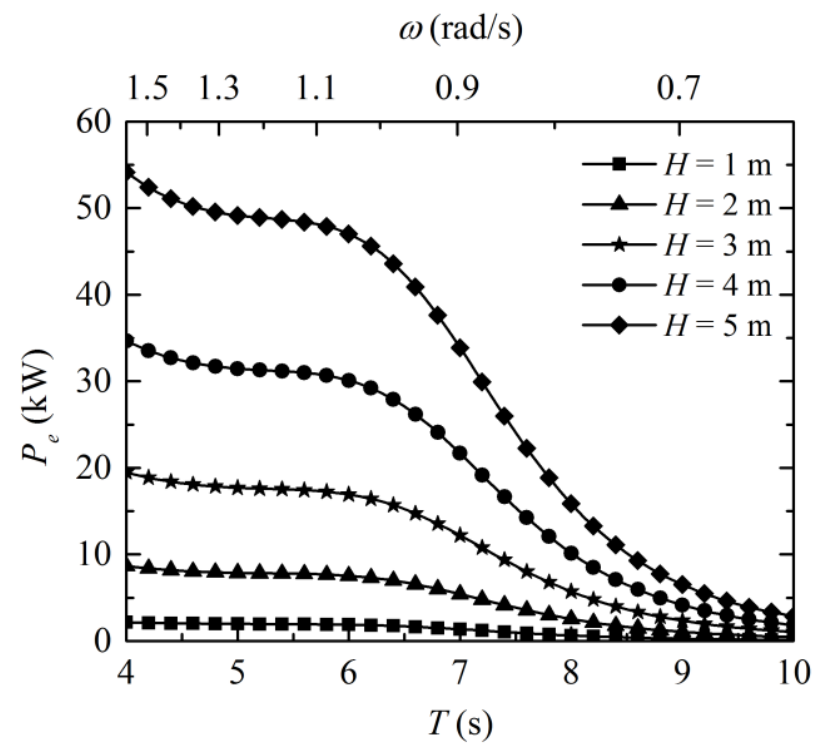

(a)

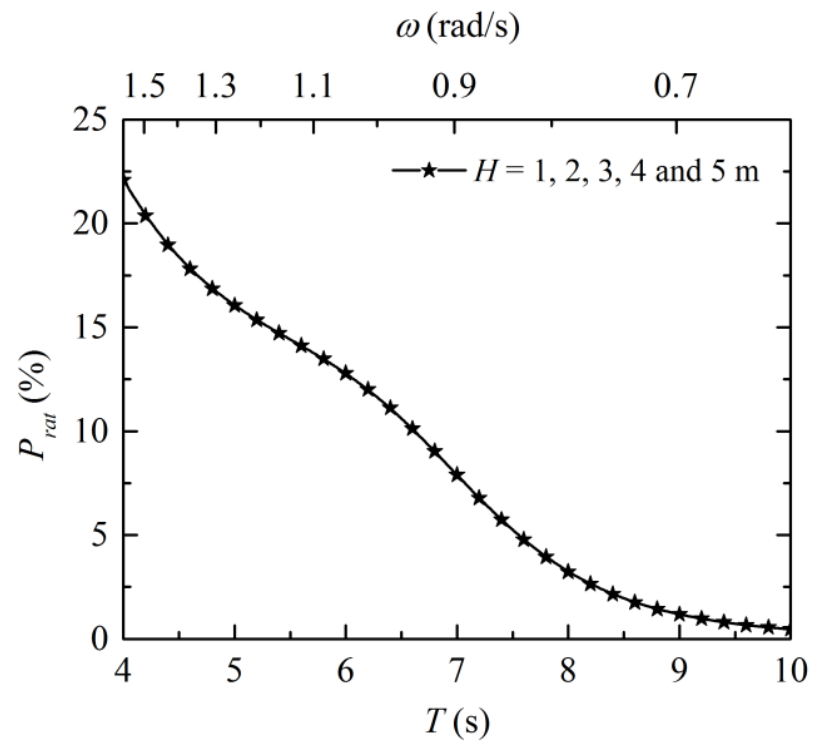

(b)

Fig. 14. Variations of generated electrical real power $P_{e}(\mathrm{a})$ and power capture ratio $P_{\text {rat }}$ (b) with wave period $T$ for different wave height 


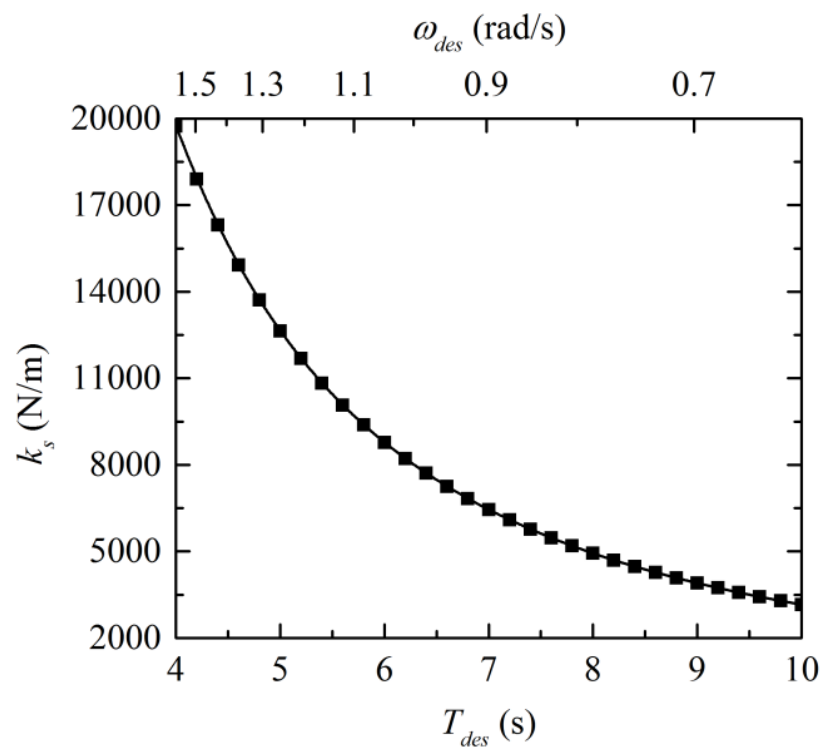

Fig. 15. Variation of spring constant $k_{s}$ with design wave period $T_{\text {des }}$ 


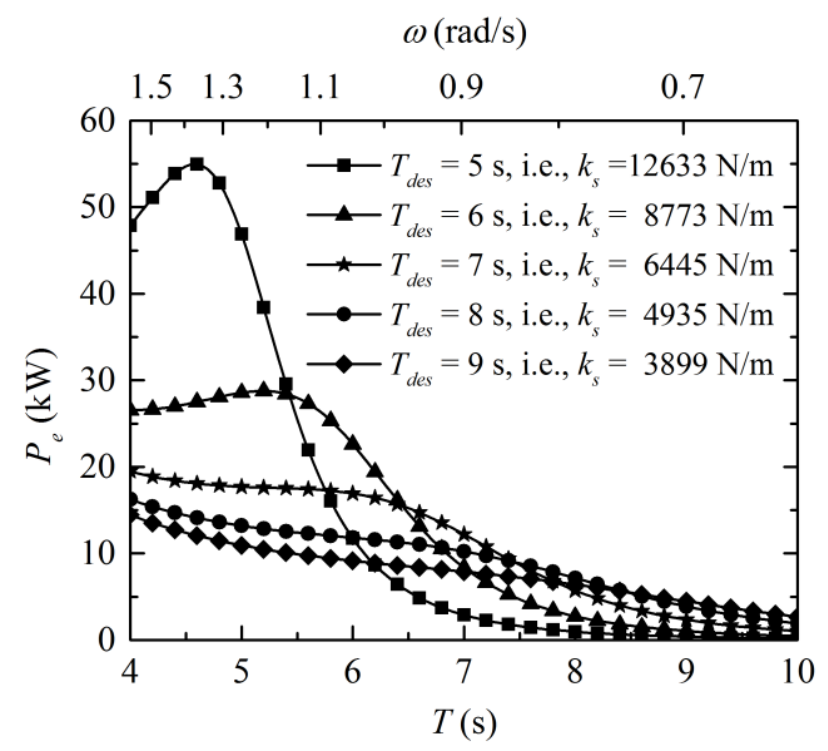

(a)

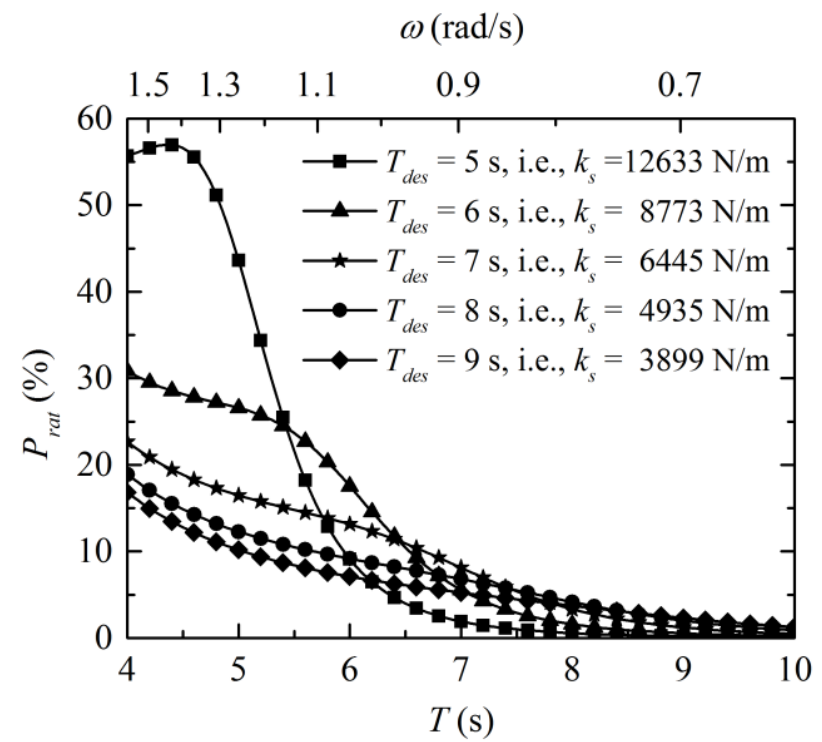

(b)

Fig. 16. Variations of generated electrical real power $P_{e}(\mathrm{a})$ and power capture ratio $P_{\text {rat }}$ (b) with wave period $T$ for different spring constant 